\title{
Resveratrol improves reproductive parameters of adult rats varicocelized in peripuberty
}

\author{
Talita Biude Mendes, Camila Cicconi Paccola, Flávia Macedo de Oliveira Neves, \\ Joana Noguères Simas, André da Costa Vaz, Regina Elisabeth L Cabral, \\ Vanessa Vendramini and Sandra Maria Miraglia
}

Laboratory of Developmental Biology, Department of Morphology and Genetics, Federal University of Sao Paulo (UNIFESP), Sao Paulo, Brazil

Correspondence should be addressed to S M Miraglia; Email: miraglia.sm@gmail.com

\begin{abstract}
The aim of this study was to investigate the protective action of resveratrol against the reproductive damage caused by left-sided experimental varicocele. There was a reduction of testicular major axis in the varicocele group when compared with the other groups; the testicular volume was reduced in varicocele group in comparison to the sham-control and resveratrol groups. The frequency of morphologically abnormal sperm was higher in varicocele and varicocele treated with resveratrol groups than in sham-control and resveratrol groups. The frequency of sperm with $\mathbf{1 0 0} \%$ of mitochondrial activity and normal acrosome integrity were lower in varicocele group than in varicocele treated with resveratrol, sham-control and resveratrol groups. Sperm motility was also reduced in varicocele group than in other groups. The sperm DNA fragmentation was higher in varicocele group than in other groups. Testicular levels of malondialdehyde were higher in varicocele and varicocele treated with resveratrol groups. The varicocele and varicocele treated with resveratrol groups had a significantly higher frequency of TUNEL-positive cells than sham-control and resveratrol groups; however, immunolabeling of the testes from varicocele treated with resveratrol group showed a lower number of apoptotic germ cells in comparison with the left testis of rats of the varicocele group. Reproductive alterations produced by varicocele from peripuberty were reduced by resveratrol in adulthood. Resveratrol should be better investigated as an adjuvant in the treatment of varicocele. Daily administration of resveratrol to rats with varicocele from peripuberty improves sperm quality in the adulthood.

Reproduction (2016) 152 23-35
\end{abstract}

\section{Introduction}

Infertility affects about $15 \%$ of couples trying to conceive and the male factor contributes to about half of these cases (Shefi \& Turek 2006). In fact, male infertility is a problem that is growing steadily, so that currently about $8 \%$ of men at reproductive age seek medical help (Miyaoka \& Esteves 2012). In this context, varicocele plays an important role as it is the most common cause of male infertility, affecting from 15 to $20 \%$ of healthy adults and adolescents worldwide (Jarow et al. 1996, Shefi \& Turek 2006, Agarwal et al. 2012), prevailing in $35 \%$ of cases of male primary infertility and in $80 \%$ of cases of secondary male infertility (Jarow et al. 1996). Studies have already suggested that it disturbs from 25 to $40 \%$ of the semen analyses (Dohle et al. 2005).

Varicocele is an abnormal dilatation of the pampiniform venous plexus in the scrotum (Casey \& Misseri 2015). It provokes a deficient blood supply, which results in venous stasis, causing hyperthermia and chronic hypoxia. In normal conditions, high rates of cell division in the spermatogenic process imply high rates of mitochondrial oxygen consumption by the seminiferous epithelium. Therefore, the poor vascularization of the testicular tissue, typically occurred in varicocele, reduces oxygen rates, then compromising mitochondrial metabolism (Aitken \& Roman 2008, Ferramosca et al. 2015). As a consequence, an increase in reactive oxygen species (ROS) production may occur, which directly affects spermatogenesis (Naughton et al. 2001, Reyes et al. 2012) and increases germ cell apoptosis, necrosis and degeneration (Nasr Esfahani \& Tavalaee 2012, Reyes et al. 2012). Thus, in the characteristic pathological process of varicocele, male infertility and oxidative stress are closely linked (Hendin et al. 1999, Miyaoka \& Esteves 2012). Oxidative stress takes place when ROS levels are greater than the intracellular antioxidants can neutralize (Kefer et al. 2009). Although low oxygen tensions characterize the testicular microenvironment, this tissue remains vulnerable to oxidative stress due to its abundance of polyunsaturated fatty acids (PUFA) and the presence of ROS-generating systems. Besides that, other metabolites may also have a negative impact on 
sperm quality when ROS production exceeds the body's antioxidant defenses, which represents a threat to the overall capacity of fertilization (Aitken \& Roman 2008, Aitken et al. 2014). Considering that the germinal cell lineage is highly sensitive and easily compromised by high levels of ROS (Aprioku 2013), it is also expected that oxidative stress harms the DNA of germ cells (Aitken et al. 2014) as well as the sperm membrane integrity, which is very vulnerable to lipid peroxidation (Hall et al. 1991).

In this context, treatment with antioxidants can be an alternative to reduce this damage or an adjunctive therapy for male infertility, including varicocele-related infertility (Hamada et al. 2013). The intake of foods rich in antioxidants by men with high levels of sperm DNA fragmentation and increased levels of ROS in the semen can improve pregnancy rates (Gil-Villa et al. 2009).

Resveratrol, a natural phytoalexin present in more than 70 kinds of fruits and leaves of edible plants (Harikumar \& Aggarwal 2008), has beneficial properties such as (a) antioxidant, by inhibiting lipid peroxidation (Gulcin 2010), (b) anti-inflammatory, (c) vasodilator, (d) anti-cancer (Jang et al. 1997), (e) estrogenic (Frémont 2000, Bhat KPL et al. 2001, de la Lastra \& Villegas 2005) and (f) antiapoptotic (Jang \& Surh 2001).

Indeed, treatment with resveratrol was able to reduce the histopathological damage and apoptosis occurrence in testicular tissue of rats with lesions caused by ischemia-reperfusion at the left side (Yulug et al. 2014). Some other studies also point to a reduction in the occurrence of apoptosis in germ cells and in the testicular lipid peroxidation in rats treated with doxorubicin and resveratrol (Türedi et al. 2015). In addition, a partial reversion of the testicular damage has been observed in resveratrol-treated rats in experimentally induced varicocele from adulthood (Abdel-Dayem 2009). Also the sperm production in healthy rats is increased by resveratrol due to its antioxidant potential (Juan et al. 2005).

The antioxidant action of resveratrol is related to the stimulation of the production of antioxidant enzymes such as catalase, superoxide dismutase and glutathione peroxidase, by modulating various signaling pathways that regulate different molecular targets (Gambini et al. 2015). Resveratrol also acts preventing the oxidation of low-density lipids and increasing the "sequestration" of free radicals; thus, it acts as a protector of cell membranes by reducing the deleterious effects of oxidative stress (Frémont 2000, Bhat KPL et al. 2001, Saiko et al. 2008, Gambini et al. 2015). Resveratrol also seems to interact with many different proteins, including cyclooxygenases, ribonucleotide reductase, kinases and DNA polymerases (Saiko et al. 2008), as well as to participate in many pathways and sets of intracellular events; therefore, it may constitute an interesting adjuvant therapy to the treatment of varicocele.
In the present research, we propose to investigate the antiapoptotic and antioxidant potential protective effects of RES against the spermatogenic damage caused by varicocele in rats, as well as its ability to improve sperm qualitative parameters such as sperm morphology, motility, mitochondrial activity, acrosome integrity and DNA integrity. The rat is a good model for varicocele induction as the insertion of its left spermatic vein in the left renal vein is positioned at a $90^{\circ}$ angle, which is anatomically similar to humans. In consequence, a partial ligature of the left renal vein can be surgically performed, inducing an increase in the venous pressure, resulting in the venous reflux into the left vein; this is further reflected in the pampiniform plexus, simulating what happens in teenager patients with varicocele (Saypol et al. 1981, Turner 2001, Zhang et al. 2008). As the sprouting of varicocele usually coincides with the onset of puberty (Skoog et al. 1997), due to the physical growth and the increase in abdominal pressure (Delaney 2004), and as such effect can produce progressive complications on the fertility (Bong \& Koo 2004), we induced varicocele in rats at peripuberty and studied the reproductive parameters at adulthood.

\section{Materials and methods}

\section{Obtainment of the animals}

Totally, 70 peripubertal male Wistar rats (Rattus norvegicus albinus) were used. They were obtained from mating animals belonging to the Center of Development of Experimental Models for Medicine and Biology (CEDEME) of the Federal University of Sao Paulo (UNIFESP) and were maintained in a local animal facility, where they were housed in polypropylene cages $(40 \times 30 \times 15 \mathrm{~cm})$ under shavings and appropriate conditions of hygiene, temperature $\left(22^{\circ} \mathrm{C} \pm 2^{\circ} \mathrm{C}\right)$, humidity $(45-55 \%)$ and light (12 h light:12 h darkness). Rat chow (Nuvilab CR-1 feed, Nuvital) and water were provided ad libitum. This study followed the ethics principles adopted by the Brazilian College of Animal Experimentation and the experiment was approved by the Ethics Committee for Animal Research of the Federal University of Sao Paulo, Brazil (CEUA no. 419454).

\section{Animals and their distribution into the groups}

Peripubertal 41-day-old rats were randomly divided into four groups: varicocele $(\mathrm{V} ; n=21)$, varicocele-resveratrol (V-RES; $n=21$ ), resveratrol (RES; $n=14$ ) and sham-control (SC; $n=14)$. The groups $\mathrm{V}$ and $\mathrm{V}$-RES were composed by animals submitted to experimental left varicocele (ELV), which was induced by a standard surgical procedure (Turner 2001) at the age of 41 days, under anesthesia (ketamine-xylazine 4:1) (DopalenAnasedan - Ceva, Sao Paulo, Brazil).

Resveratrol was given in a daily dose $(300 \mathrm{mg} / \mathrm{kg}$ body weight; by gavage) to the animals of the groups $\mathrm{V}$-RES and RES, from 42 to 100 days of age. The phytoalexin was obtained in its most stable form, trans-resveratrol (Domínguez et al. 2001, Chen et al. 2007, Das et al. 2008), which is extracted from the 
roots of Polygonum cuspidatum (Sieb-Xi'an Pharmpro Union Co., Ltd., Xi'an, China). Trans-resveratrol is stable for at least $42 \mathrm{~h}$ (Trela \& Waterhouse 1996). The animals of the shamcontrol group were submitted to the same surgical procedure, at 41 days of age; however, they were not submitted to the partial ligature of the left renal vein. Carboxymethyl cellulose (resveratrol's diluent) was also given by gavage to these rats from 42 to 100 days of age. All animals that were submitted to a surgical procedure (V, V-RES and SC) were carefully monitored and orally treated with Ibuprofen at a dose of $20 \mathrm{mg} / \mathrm{kg}$ body weight (gavage) (Hawk et al. 2005) for five subsequent days after the surgery. Only animals that showed significant dilatation of the left spermatic vein on the day of killing (100 days of age) were used to compose the $V$ and $V$-RES groups. According to Turner (2001), this technique has about $10 \%$ failure in the formation of varicocele. The rats that presented no dilatation of the left spermatic vein or that had renal atrophy were excluded from the experiment (about 14\%).

\section{Biometric and histological analyses}

The testes, epididymides, prostate and seminal vesicles (empty and full) were collected and weighed using a semi-analytical electronic scale (Marte-AS1000). The testicular volume was acquired according to the Scherle's method (Scherle 1970). The relative weight of the testes, prostate and seminal vesicles were calculated (organ weight/100g body weight). As testis is an ellipsoid of revolution organ, the measurements of the major and minor axes of both testes (Miraglia \& Hayashi 1993) were also obtained using a digital caliper (INSIZE-1112-150). In the groups submitted to ELV (V and V-RES groups), left (side of the varicocele surgery, i.e., ipsilateral side) and right (contralateral side to the surgical procedure) testes were separately analyzed and respectively denominated in the results using the acronyms VI, Vr, VI-RES and Vr-RES

The testes were fixed by $24 \mathrm{~h}$ immersion in Bouin's fixative. In sequence, testicular fragments were processed for paraffin-embedding. For histopathological analysis, two isotropic $4 \mu \mathrm{m}$-thick testicular sections were obtained and submitted to the periodic acid-Schiff histochemical method and counterstained with hematoxylin (PAS+H). Two sections were analyzed per animal using a Leica Qwin-V3 image analysis system (Leica - Cambridge, UK) under either $\times 40$ or $\times 100$ objective lenses; the testicular sections were completely scrutinized and the images captured using a digital camera connected to a light microscope. In addition, $7 \mu \mathrm{m}$-thick testicular sections were obtained and submitted to the TUNEL (Terminal deoxynucleotidyl transferase-mediated dUPT NickEnd Labeling) immunoenzymatic method for labeling of apoptotic cells and a subsequent stereological analysis as described previously by Stumpp et al. (2004).

\section{Sperm morphology}

To evaluate the sperm morphology, samples of $3 \mu \mathrm{L}$ fresh fluid were collected from the epididymal cauda and homogenized in $2 \mathrm{~mL}$ distilled water. From this homogenate, smears were obtained on glass slides and stained by Schorr/hematoxylin method (Shorr 1941). The morphological analysis of the sperms contained in these smears was processed under light microscope at $500 \times$ final magnification. Two-hundred sperms were randomly evaluated and the morphological abnormalities (head shape, isolated heads and tail defects) were performed according to the description of Filler et al. (1993) and Miranda-Spooner et al. (2016).

\section{Sperm mitochondrial activity}

The mitochondrial activity was assessed using the 3,3'-diaminobenzidine (DAB) staining method proposed by Hrudka (1987). This technique is based on the oxidation of 3,3'-diaminobenzidine by the cytochrome $c$ oxidase enzyme, when the reactant is polymerized and deposited on mitochondrial sheath along the sperm midpiece (Hrudka 1987). Initially, a sample of $50 \mathrm{~mL}$ epididymal cauda fluid was added to a solution containing $1 \mathrm{mg} / \mathrm{mL}$ DAB in phosphate buffer solution (PBS; $137 \mathrm{mM} \mathrm{NaCl}, 2.7 \mathrm{mM} \mathrm{KCl}, 4.3 \mathrm{mM} \mathrm{Na}{ }_{2} \mathrm{HPO}_{4}, 1.4 \mathrm{mM}$ $\mathrm{KH}_{2} \mathrm{PO}_{4}, \mathrm{pH}=7.4$ ) in a ratio of $1: 2$ and incubated for $1 \mathrm{~h}$, in the dark and in a water bath at $37^{\circ} \mathrm{C}$. Negative controls were done to avoid nonspecific staining of the intermediate piece; for this goal, an aliquot of epididymal fluid was previously inactivated at $70^{\circ} \mathrm{C}$, for $5 \mathrm{~min}$. After incubation, $10 \mu \mathrm{L}$ of the aliquots were smeared on glass slides (Precision Glass Line, Shanghai, China) and air dried; after drying, the smears containing the sperms were fixed in $10 \%$ formaldehyde for $10 \mathrm{~min}$, washed with distilled water and allowed to dry again at room temperature. Subsequently, microscope coverslips were placed on a synthetic resin (Novo Entellan - Merck KGaA, Darmstadt, Germany).

Two-hundred sperms were analyzed under a phase-contrast microscope (Olympus BX-51 - Tokyo, Japan). The evaluation was based on the classification proposed by Hrudka (1987), as formerly commented: class I (intermediate piece with $100 \%$ of staining), class II (over $50 \%$ of staining in the intermediate piece), class III (less than $50 \%$ of staining in the intermediate piece) and class IV (absence of staining in the intermediate piece).

\section{Acrosome integrity}

Soon after the withdrawal of the epididymis, its caudal portion was dissected, isolated and cleaned. Sperm samples were collected and stored as described previously by Vendramini et al. (2012).

The acrosome integrity was assessed based on the methodology described by Varisli et al. (2009), with some minor modifications. To determine the acrosome integrity, we carried out the staining using 'PNA Lectin from Arachis hypogaea (peanut), Alexa Fluor 488 Conjugate' (Molecular Probes).

On the day of analysis, samples were thawed and transferred (50 mL each) to a catalogued Eppendorf dark tubes containing Alexa Fluor $488100 \mathrm{~mL}$ PNA (20 ng/mL). The samples with dye were incubated at $37^{\circ} \mathrm{C}$ for $30 \mathrm{~min} ; 20 \mu \mathrm{L}$ samples were seeded on glass microscope slides and analyzed in an epifluorescence microscope Nikon Eclipse Cl (Nikon) with appropriate filter. Two-hundred sperms were quantified per slide and were classified as: (a) intact (sperm exhibiting intense and moderately bright fluorescence in the acrosome region) and (b) altered (sperm showing weak fluorescence, irregular or absent in the acrosome region). 
Table 1 Testicular and epididymal biometric analysis obtained from control and experimental groups (SC, RES, V and V-RES) when they were 100 days old, considering each side (contralateral, r; ipsilateral, I) in the ELV induction ( $\mathrm{Vr}$ and $\mathrm{Vr}$ - RES; $\mathrm{VI}$ and $\mathrm{VI}-\mathrm{RES}$ ). Data are presented as mean \pm S.D. or as median (IQR: Q1-Q3).

\begin{tabular}{|c|c|c|c|c|c|c|}
\hline \multirow[b]{2}{*}{ Parameters } & \multicolumn{6}{|c|}{ Groups $(n=7)$} \\
\hline & SC & RES & $\mathrm{Vr}$ & $\mathrm{Vl}$ & Vr-RES & VI-RES \\
\hline \multicolumn{7}{|l|}{ Epididymis } \\
\hline Absolute weight $(\mathrm{mg})^{\mathrm{a}}$ & $644.29 \pm 48.94$ & $631.43 \pm 60.12$ & $650.00 \pm 78.95$ & $684.29 \pm 31.55$ & $612.86 \pm 77.83$ & $610.26 \pm 82.26$ \\
\hline Relative weight $(\mathrm{mg} \%)^{\mathrm{a}}$ & $0.16 \pm 0.01$ & $0.16 \pm 0.01$ & $0.17 \pm 0.01$ & $0.18 \pm 0.02$ & $0.16 \pm 0.02$ & $0.16 \pm 0.01$ \\
\hline \multicolumn{7}{|l|}{ Testicular } \\
\hline Absolute weight $(g)^{b}$ & $1.70(1.66-1.80)$ & $1.72(1.66-1.8)$ & $1.62(1.50-1.73)$ & $1.68(1.57-1.75)$ & $1.70(1.64-1.75)$ & $1.76(1.71-1.80)$ \\
\hline Relative weight $(\mathrm{g} \%)^{\mathrm{b}}$ & $0.43(0.42-0.46)$ & $0.46(0.43-0.46)$ & $0.40(0.38-0.46)$ & $0.43(0.39-0.50)$ & $0.43(0.42-0.47)$ & $0.45(0.44-0.49)$ \\
\hline Volume $\left(\mathrm{cm}^{3}\right)^{\mathrm{b}}$ & $1.63(1.51-1.70)$ & $1.58(1.52-1.65)$ & $1.43(1.39-1.56)$ & $1.50(1.38-1.55)$ & $1.54(1.51-1.60)$ & $1.55(1.50-1.60)$ \\
\hline Major axis $(\mathrm{mm})^{\mathrm{a}}$ & $20.68 \pm 0.55$ & $21.03 \pm 0.86$ & $19.53 \pm 0.91^{\mathrm{c}}$ & $19.85 \pm 0.63^{\mathrm{d}}$ & $20.55 \pm 0.57$ & $21.15 \pm 0.61$ \\
\hline Minor axis $1(\mathrm{~mm})^{\mathrm{a}}$ & $11.55 \pm 0.37$ & $11.21 \pm 0.59$ & $10.96 \pm 0.46$ & $11.13 \pm 0.76$ & $11.13 \pm 0.30$ & $11.18 \pm 0.30$ \\
\hline Minor axis $2(\mathrm{~mm})^{\mathrm{a}}$ & $12.19 \pm 0.48$ & $12.35 \pm 0.25$ & $11.98 \pm 0.54$ & $12.09 \pm 0.70$ & $11.97 \pm 0.25$ & $12.08 \pm 0.22$ \\
\hline
\end{tabular}

${ }^{\mathrm{a} A N O V A}$ and SNK. ${ }^{\mathrm{b}}$ Analysis of Kruskal-Wallis and Dunn's test. ' $\mathrm{Vr}<\mathrm{SC}, \mathrm{RES}, \mathrm{Vr}-\mathrm{RES}$ and $\mathrm{VI}-\mathrm{RES}$; ${ }^{\mathrm{d}} \mathrm{VI}<\mathrm{RES}$ and $\mathrm{VI}-\mathrm{RES}(P<0.05)$.

\section{Sperm motility}

The sperm motility was evaluated using a computerized sperm analysis system (computer-assisted sperm analysis - CASA) and following the methodology described by Klinefelter et al. (1991), with some modifications (Miranda-Spooner et al. 2016). For this goal, after the dissection, the epididymal cauda was removed and subsequently transferred to $35 \mathrm{~mm}$ culture plates, containing Hank's balanced salt solution (HBSS - 136,8 mM NaCl, 5,4 mM $\mathrm{KCl}, 0,3 \mathrm{mM} \mathrm{Na} 2 \mathrm{HPO} 4,0,5 \mathrm{mM} \mathrm{KH} 2 \mathrm{PO} 4,12 \mathrm{mM}$ NaHCO3, $\mathrm{pH} 7,3)$, which was supplemented with $2 \mathrm{mg} / \mathrm{mL}$ BSA. The plates were left for $30 \mathrm{~min}$ at $37^{\circ} \mathrm{C}$ in order that the spermatozoa could move into the culture medium. Then, an aliquot of this medium containing sperms was drawn by capillary action into a pre-warmed chamber slide with a depth of $100 \mu \mathrm{m}$ (LEJA Standard Count, Nieuw-Vennep, The Netherlands). The slides containing the sperms were placed into a Hamilton Thorne Integrated Visual Optical System (HTM-IVOS; Hamilton-Thorne Research, Beverly, MA, USA) with specific software for rat sperm analyses (Toxicology System, version 12, HamiltonThorn Biosciences). The motion parameters investigated were percentage of motile sperm, curvilinear velocity (VCL), average path velocity (VAP), straight-line velocity (VSL), amplitude of lateral head displacement (ALH), beat cross frequency (BCF), linearity (LIN) and straightness (STR).

\section{Sperm DNA fragmentation (comet assay)}

The sperm DNA fragmentation was evaluated using the Comet assay as described previously (Codrington et al. 2004, Vendramini et al. 2012) and with minor changes (MirandaSpooner et al. 2016).

Samples containing sperm, from the same pool used for the acrosome reaction, were thawed and diluted in $0.5 \%$ low melting point agarose (LGC Laboratories, Sao Paulo, SP, Brazil), pre-warmed $\left(37^{\circ} \mathrm{C}\right)$ at a concentration of $4 \times 10^{6}$ cells $/ \mathrm{mL}$. An aliquot $(125 \mu \mathrm{L})$ of the solution was placed on slides pre-coated with $1 \%$ normal melting point agarose (LGC Laboratories, Sao Paulo, SP, Brazil). The second lysis buffer $\left(37^{\circ} \mathrm{C}\right)$, which contained proteinase $\mathrm{K}(0.1 \mathrm{mg} / \mathrm{mL})$, was used to cover the slides for $2 \mathrm{~h}$ and $30 \mathrm{~min}$ at $37^{\circ} \mathrm{C}$. The horizontal electrophoresis was performed using TBE buffer at $30 \mathrm{~V}(1.3 \mathrm{v} / \mathrm{cm})$ (Vendramini et al. 2013). Finally, the slides were fixed with pre-chilled

Table 2 Biometric analysis of testis, epididymis, seminal vesicle and prostate obtained from control and experimental groups (SC, RES, $V$ and V-RES) when they were 100 days old, considering the both testes in ELV induction (V and V-RES groups). Data are presented as mean \pm S.D. or as median (IQR: Q1-Q3).

\begin{tabular}{|c|c|c|c|c|}
\hline \multirow[b]{2}{*}{ Parameters } & \multicolumn{4}{|c|}{ Groups $(n=7)$} \\
\hline & SC & RES & $\mathrm{V}$ & V-RES \\
\hline Body weight $(g)^{a}$ & $404.29 \pm 31.47$ & $388.43 \pm 37.10$ & $383.43 \pm 35.35$ & $374.86 \pm 36.34$ \\
\hline Absolute epididymis weight (mg) ${ }^{\mathrm{a}}$ & $644.29 \pm 48.94$ & $631.43 \pm 60.12$ & $667.14 \pm 30.39$ & $611.43 \pm 76.90$ \\
\hline Relative epididymis weight $(\mathrm{mg} \%)^{\mathrm{a}}$ & $0.16 \pm 0.01$ & $0.16 \pm 0.01$ & $0.17 \pm 0.01$ & $0.16 \pm 0.01$ \\
\hline Absolute ventral prostate weight $(\mathrm{mg})^{\mathrm{a}}$ & $588.57 \pm 49.81$ & $577.14 \pm 134.37$ & $648.57 \pm 164.66$ & $528.57 \pm 115.82$ \\
\hline Relative ventral prostate weight $(\mathrm{mg} \%)^{\mathrm{a}}$ & $0.15 \pm 0.02$ & $0.15 \pm 0.03$ & $0.17 \pm 0.03$ & $0.14 \pm 0.03$ \\
\hline Absolute full seminal vesicle $(g)^{b}$ & $1.15(1.05-1.22)$ & $1.31(1.14-1.46)$ & $1.25(1.06-1.50)$ & $1.26(1 . \overline{2} 2-1.29)$ \\
\hline Relative full seminal vesicle $(\mathrm{g} \%)^{\mathrm{a}}$ & $0.29 \pm 0.04$ & $0.35 \pm 0.08$ & $0.34 \pm 0.07$ & $0.33 \pm 0.03$ \\
\hline Absolute empty seminal vesicle (mg) & $540(450-580)$ & $520(480-550)$ & $550(470-570)$ & $480(440-570)$ \\
\hline Relative empty seminal vesicle $(\mathrm{mg} \%)^{b}$ & $0.14(0.11-0.15)$ & $0.13(0.12-0.15)$ & $0.14(0.12-0.16)$ & $0.13(0.11-0.16)$ \\
\hline \multicolumn{5}{|l|}{ Testicular } \\
\hline Absolute weight $(\mathrm{g})^{\mathrm{a}}$ & $1.75 \pm 0.12$ & $1.75 \pm 0.12$ & $1.63 \pm 0.13$ & $1.72 \pm 0.06$ \\
\hline Relative weight $(\mathrm{g} \%)^{\mathrm{b}}$ & $0.43(0.42-0.46)$ & $0.46(0.43-0.46)$ & $0.42(0.39-0.47)$ & $0.44(0.43-0.48)$ \\
\hline Volume $\left(\mathrm{cm}^{3}\right)^{\mathrm{a}}$ & $1.62 \pm 0.11$ & $1.62 \pm 0.13$ & $1.44 \pm 0.12^{\mathrm{c}}$ & $1.55 \pm 0.07$ \\
\hline Major axis $(\mathrm{mm})^{\mathrm{a}}$ & $20.68 \pm 0.55$ & $21.03 \pm 0.86$ & $19.69 \pm 0.60^{d}$ & $20.84 \pm 0.53$ \\
\hline Minor axis $1(\mathrm{~mm})^{\mathrm{a}}$ & $11.55 \pm 0.37$ & $11.21 \pm 0.59$ & $11.05 \pm 0.48$ & $11.16 \pm 0.27$ \\
\hline Minor axis $2(\mathrm{~mm})^{\mathrm{a}}$ & $12.19 \pm 0.48$ & $12.35 \pm 0.25$ & $12.04 \pm 0.53$ & $12.02 \pm 0.21$ \\
\hline
\end{tabular}

${ }^{\mathrm{a} A N O V A}$ and SNK. ${ }^{\mathrm{b}}$ Analysis of Kruskal-Wallis and Dunn's test. ${ }^{\mathrm{C}} \mathrm{V}<\mathrm{SC}$ and RES; ${ }^{\mathrm{d}} \mathrm{V}<\mathrm{SC}$, RES and V-RES $(P<0.05)$. 

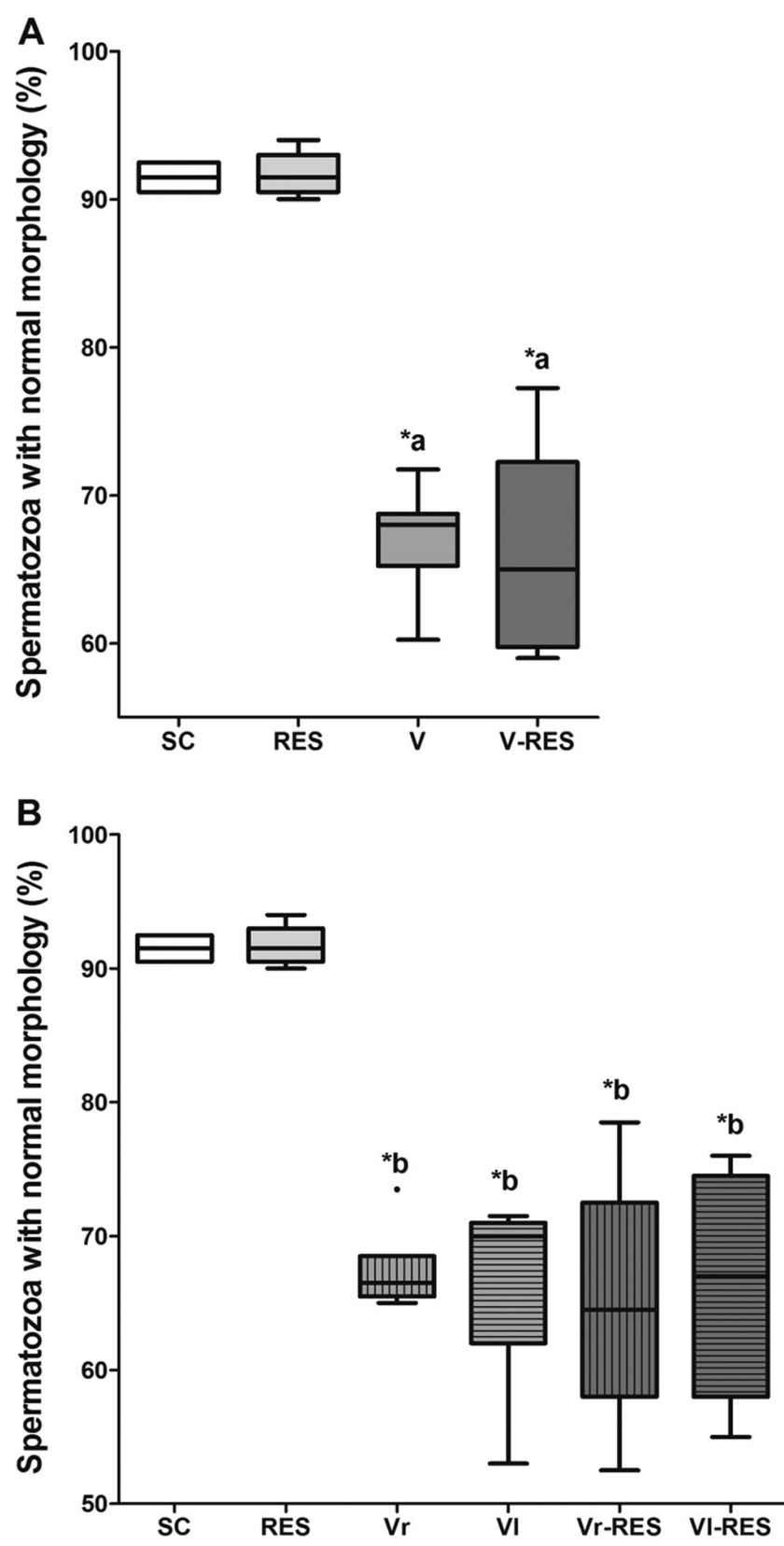

Figure 1 Percentage of spermatozoa with normal morphology in $\mathrm{SC}$, RES, V, and V-RES groups (A) and in SC, RES, Vr, VI (sides in the $\mathrm{V}$ group), $\mathrm{Vr}$-RES, and VI-RES (sides in the V-RES group) (B) $(n=7)$. Values are expressed as median and interquartile range (Q1 - Q3). Analysis of Kruskal-Wallis and Dunn's test $(P<0.05)$. *a SC and RES $>\mathrm{V}$ and $\mathrm{V}$-RES; ${ }^{*} \mathrm{~b} \mathrm{SC}$ and RES $>\mathrm{Vr}, \mathrm{VI}, \mathrm{Vr}$-RES and VI-RES.

$70 \%$ ethanol, air dried and stored in the dark until analysis (Haines et al. 2002).

On the day of analysis, the samples were stained with ethidium bromide $(2 \mu \mathrm{L} / 1.5 \mathrm{~mL}$ PBS/slide) and analyzed under a epifluorescence microscope Nikon Eclipse Cl (Nikon - Tokyo, Japan); 50 cells were analyzed per slide (two slides per animal), using the specific image analysis system for Comet assay (Comet Assay LUCIA, v.7.02.00, Praha, Czech Republic). The following parameters were analyzed: DNA in the cauda
$(\%)$, tail length and tail extent moment (tail length $\times$ cauda DNA \%/100) and olive tail moment (cauda DNA\% $\times$ a fraction of the tail length/100).

\section{Analysis of the lipid peroxidation, at the testicular level, by dosage of malondialdehyde (MDA)}

On the day of killing, the testes were removed and decapsulated and $0.1 \mathrm{~g}$ samples were frozen at $-20^{\circ} \mathrm{C}$. These samples were thawed and homogenized in $1.15 \% \mathrm{KCl}$ solution.

A sample of $0.1 \mathrm{~mL}$ of the testicular homogenate was added to a tube containing $1.5 \mathrm{~mL}$ acetic acid (20\%, pH 3.5), $0.2 \mathrm{~mL}$ sodium dodecyl sulfate (SDS: $8.1 \%$ ), $1.5 \mathrm{~mL}$ 2-thiobarbituric acid (TBA: $0.8 \%$ ) and $0.7 \mathrm{~mL}$ water. The tubes were shaken and incubated in a water bath at $95^{\circ} \mathrm{C}$ for $60 \mathrm{~min}$. Subsequently, the tubes were cooled and centrifuged at $1878 \mathrm{~g}$ for $10 \mathrm{~min}$. The samples were placed in plates for analysis using the Enzyme-Linked Immunosorbent Assay (ELISA) and the absorbance was measured at $532 \mathrm{~nm}$. The concentrations are expressed as malondialdehyde $\mathrm{nmol} / \mathrm{g}$ tissue according to the methodology described by Abd-Allah et al. (2009).

\section{Statistical method}

The results were statistically analyzed using the Sigma Plot 12.0 software. The values with normal distribution were analyzed according to the parametric test one-way analysis of variance (ANOVA) aiming to compare the different groups (SC, RES, $V$ and $V$-RES). When the differences were significant, the Student-Newman-Keuls test (SNK) was also used. However, when the values did not show normal distribution and similarity of variance, they were submitted to the non-parametric test of analysis of variance, the Kruskal-Wallis test; in this case, when the results were significant, a post-test for multiple comparisons was applied (Dunn's test or the SNK test). Differences were considered significant when $P<0.05$.

\section{Results}

\section{Resveratrol promoted some improvement of testis volume in varicocelized rats}

Tables 1 and 2 show the body weight and the biometric data of testes, epididymides, seminal vesicles (full and empty) and prostate obtained from the control and experimental groups. In Table 1, the testicular and epididymal data were presented considering the ipsilateral (I) and contralateral (r) sides to the surgery of varicocele induction.

Our results showed a significant reduction of testicular volume in varicocelized rats ( $\mathrm{V}$ group) in comparison with sham-control (SC) and resveratrol (RES) groups. The treatment with resveratrol given to varicocelized rats (V-RES group) showed a trend of improvement of this parameter; although not significant $(P=0.078)$, the mean testicular volume was higher than in $\mathrm{V}$ group. In addition, it did not differ from the SC and RES groups (Table 2).

The reduction of testicular volume in the $\mathrm{V}$ group, in comparison to the SC and RES groups, was a result of the 
Table 3 Analysis of mitochondrial activity in control and experimental groups (SC, RES, V, and V-RES) when they were 100 days old, considering the both testes in ELV induction (V and V-RES). Data are presented as mean \pm S.D. or as median (IQR: Q1-Q3).

\begin{tabular}{|c|c|c|c|c|}
\hline Groups $(n=7)$ & Class I $(\%)^{\mathrm{a}}$ & Class II $(\%)^{\mathrm{a}}$ & Class III $(\%)^{b}$ & Class IV $(\%)^{b}$ \\
\hline SC & $89.93 \pm 4.77$ & $8.86 \pm 4.0$ & $0.5(0.0-3.0)$ & $0.0(0.0-0.0)$ \\
\hline RES & $93.86 \pm 3.35$ & $5.36 \pm 2.85$ & $1.0(0.0-1.5)$ & $0.0(0.0-0.0)$ \\
\hline $\mathrm{V}$ & $38.18 \pm 8.48^{c}$ & $44.79 \pm 4.79^{d}$ & $15.5(9.25-19.75)^{d}$ & $1.5(0.25-2.0)^{\mathrm{e}}$ \\
\hline V-RES & $63.57 \pm 9.17^{c}$ & $29.21 \pm 6.04^{d}$ & $5.75(3.5-7.25)^{d}$ & $0.25(0.0-1.0)$ \\
\hline
\end{tabular}

${ }^{a}$ ANOVA and SNK. ${ }^{b}$ Analysis of Kruskal-Wallis and Dunn's test. ${ }^{c} \mathrm{~V}<\mathrm{V}-\mathrm{RES}<\mathrm{SC}$ and RES; ${ }^{\mathrm{d}} \mathrm{V}>\mathrm{V}-\mathrm{RES}>\mathrm{SC}$ and RES; $\mathrm{eV}>\mathrm{SC}$ and RES $(P<0.05)$.

reduction occurred in its major axis (Table 2), as the testis is an ellipsoid model. This change also occurred when each side of the testis was individually analyzed (Table 1).

\section{The incidence of sperm anomalous forms found in varicocelized rats was not improved by resveratrol}

The frequency of sperms with normal morphology was lower in the varicocelized rats (V and V-RES groups) than in the SC and RES groups (Fig. 1A). When each epididymis side (ipsilateral and contralateral) was individually considered, differences were still evident in both epididymides in comparison to the SC and RES groups (Fig. 1B). Many types of abnormalities of head (banana-shaped, detached, backward bent) and of tail (coiled, bent, broken) were observed in the spermatozoa of varicocelized rats both in $\mathrm{V}$ and $\mathrm{V}$-RES groups. Besides, spermatozoa with multiple defects were also noted in these groups but very rarely observed in the SC and RES groups. The most frequent changes that occurred in $\mathrm{V}$ and $V$-RES groups were bent tail, sperm head detachment from its tail and banana-shaped head sperm.

\section{Resveratrol improved sperm mitochondrial activity in varicocelized rats}

The rats of the $\mathrm{V}$ and $\mathrm{V}$-RES groups showed alterations in the mitochondrial activity when compared with the SC and RES groups such as (i) increased frequencies of class II (more than $50 \%$ of the midpiece was stained) and class III sperm (less than $50 \%$ of the midpiece was stained) and (ii) reduced frequency of class I sperm $(100 \%$ of the midpiece was stained). These results showed that varicocelized rats of both groups had higher number of sperms with inactive mitochondria in comparison to SC and RES groups. However, in the varicocelized rats treated with resveratrol (V-RES group), the quantity of sperms with active mitochondria (class I) was higher than in the $\mathrm{V}$ group, whereas the frequencies of class II and III sperms were lower than in rats that did not receive the treatment (Table 3 ).

However, the frequency of class IV sperms (absence of mitochondrial activity) was just altered in the $V$ group.

The same alterations were observed when each epididymis cauda side was individually analyzed (Table 4), producing the same relationships among the groups as described above. When the mitochondrial activity was measured in the sperms from the ipsilateral side and it was compared with the contralateral side, no significant alterations of these parameters (class I-IV sperms) were observed in the varicocelized animals of the same group $(\mathrm{VI}-\mathrm{RES} \times \mathrm{Vr}$-RES and $\mathrm{VI} \times \mathrm{Vr}$ ).

\section{Resveratrol raised sperm total motility to control levels in varicocelized rats}

As shown in Table 5, the treatment with resveratrol improved the sperm motility of the varicocelized (V-RES group) as it was higher than the one noted in the $\mathrm{V}$ group and raised sperm total motility to control levels (Table 5).

When each epididymis was individually analyzed, sperms collected from the contralateral epididymal cauda of the varicocelized rats treated with resveratrol (Vr-RES group) showed higher motility when compared with the sperms from both ipsilateral $(\mathrm{VI})$ and contralateral $(\mathrm{Vr})$ sides of the varicocelized rats, which were not treated with resveratrol ( $\mathrm{V}$ group). Also, there was an improvement in the sperm motility from the ipsilateral epididymal cauda in the group treated with resveratrol (VI-RES) in comparison to the ipsilateral side of the $\mathrm{V}$ group $(\mathrm{VI})$ (Table 6).

Table 4 Analysis of mitochondrial activity from control and experimental groups (SC, RES, V and V-RES) when they were 100 days old, considering each side (contralateral, $r$; ipsilateral, I) in the ELV induction ( $\mathrm{Vr}$ and $\mathrm{Vr}$-RES; $\mathrm{VI}$ and $\mathrm{VI}-\mathrm{RES})$. Data are presented as mean \pm S.D. or as median (IQR: Q1-Q3).

\begin{tabular}{|c|c|c|c|c|}
\hline Groups $(n=7)$ & Class I $(\%)^{\mathrm{a}}$ & Class II $(\%)^{b}$ & Class III $(\%)^{b}$ & Class IV $(\%)^{b}$ \\
\hline SC & $89.93 \pm 4.77$ & $10.0(4.5-12.5)$ & $0.5(0.0-3.0)$ & $0.0(0.0-0.0)$ \\
\hline RES & $93.86 \pm 3.35$ & $5.0(2.5-7.5)$ & $1.0(0.0-1.5)$ & $0.0(0.0-0.0)$ \\
\hline $\mathrm{Vr}$ & $39.71 \pm 8.28^{c}$ & $45.0(40.5-46.5)^{d}$ & $10.5(9-19.5)^{d}$ & $1.5(0.5-3.0)^{\mathrm{e}}$ \\
\hline $\mathrm{VI}$ & $36.64 \pm 10.72^{c}$ & $44.0(41-48.5)^{\mathrm{d}}$ & $17.0(11.5-21.5)^{\mathrm{d}}$ & $1.5(0.5-2.0)^{\mathrm{e}}$ \\
\hline Vr-RES & $64.00 \pm 10.21^{c}$ & $28.0(25.0-30.0)^{\mathrm{d}}$ & $5.0(2.5-8.0)^{d}$ & $0.0(0.0-1.5)$ \\
\hline VI-RES & $63.14 \pm 10.80^{c}$ & $32.0(30.5-37.5)^{d}$ & $6.0(4.5-9.0)^{\mathrm{d}}$ & $0.5(0.0-0.5)$ \\
\hline
\end{tabular}

${ }^{a} A N O V A$ and SNK. ${ }^{b}$ Analysis of Kruskal-Wallis and Dunn's test. ${ }^{c} \mathrm{Vr}$ and $\mathrm{VI}<\mathrm{Vr}$-RES and $\mathrm{VI}-\mathrm{RES}<\mathrm{SC}$ and RES; ${ }^{\mathrm{d}} \mathrm{Vr}$ and $\mathrm{VI}>\mathrm{Vr}-\mathrm{RES}$ and $\mathrm{VI}-\mathrm{RES}>$ $\mathrm{SC}$ and RES; ${ }^{\mathrm{V}} \mathrm{V}$ and $\mathrm{VI}>\mathrm{SC}$ and RES $(P<0.05)$. 
Table 5 Data on sperm motility (CASA HTM-IVOS) of animals in the control and experimental groups when they were 100 days old.

\begin{tabular}{lcccc}
\hline & \multicolumn{4}{c}{ Groups $(n=7)$} \\
\cline { 2 - 5 } Parameters & SC & RES & V & V-RES \\
\hline Motility $(\%)^{\mathrm{a}}$ & $97(94-97)$ & $98(94-98)$ & $87(78-89)^{\mathrm{c}}$ & $96(94-97)$ \\
VAP $(\mu \mathrm{m} / \mathrm{s})^{\mathrm{b}}$ & $247.9(238.8-265.9)$ & $247.8(215.4-259.3)$ & $234.8(222.4-250.2)$ & $255.1(244.5-264.9)$ \\
VSL $(\mu \mathrm{m} / \mathrm{s})^{\mathrm{b}}$ & $198.5(180.1-203.7)$ & $186.6(167.3-193.9)$ & $175.5(167.7-184.3)$ & $192.8(184.3-201.1)$ \\
VCL $(\mu \mathrm{m} / \mathrm{s})^{\mathrm{a}}$ & $377.3 \pm 40.4$ & $368.3 \pm 35.74$ & $340.1 \pm 27.8$ & $383.8 \pm 20.22$ \\
ALH $(\mu \mathrm{m})^{\mathrm{b}}$ & $13.9(11.4-15.2)$ & $13.4(12.5-14.9)$ & $11.5(11.2-11.9)$ & $14.2(12.8-14.6)$ \\
BCF $(\mathrm{Hz})^{\mathrm{a}}$ & $13.33 \pm 2.2$ & $13.9 \pm 2.52$ & $13.65 \pm 2.61$ & $13.32 \pm 1.08$ \\
STR $(\%)^{\mathrm{a}}$ & $73.29 \pm 2.43$ & $72.87 \pm 2.03$ & $75.0 \pm 2.14$ & $72.91 \pm 0.86$ \\
LIN $(\%)^{\mathrm{a}}$ & $51.29 \pm 2.14$ & $50.12 \pm 2.64$ & $53.64 \pm 2.37$ & $50.68 \pm 1.33$ \\
\hline
\end{tabular}

${ }^{a}$ ANOVA and SNK. ${ }^{b}$ Analysis of Kruskal-Wallis and Dunn's test. ${ }^{c} S C$, RES and V-RES $>V(P<0.05)$. VAP, average path velocity; VSL, straight-line velocity; $\mathrm{VCL}$, curvilinear velocity; ALH, amplitude of lateral head displacement; BCF, beat cross frequency; STR, straightness; LIN, linearity.

\section{Resveratrol improved acrosome integrity in rats with varicocele}

Using the staining with PNA, our data show that treatment with resveratrol in varicocelized rats (V-RES group) promoted an improvement of acrosome integrity compared with the $V$ group (Fig. 2A). However, both the varicocelized rats ( $\mathrm{V}$ and $\mathrm{V}$-RES groups) had a lower frequency of sperms with acrosome integrity than the sham-control and resveratrol groups. Significant differences relating to this parameter were not observed when sperms originated from both ipsilateral and contralateral epididymal cauda of the $\mathrm{V}$ and $\mathrm{V}$-RES groups were compared (Fig. 2B).

\section{Resveratrol reduced sperm DNA fragmentation caused by varicocele}

The Comet assay showed that the $\mathrm{V}$ group had an increase in all parameters relating to the DNA fragmentation (tail DNA percentage, comet tail length, comet tail extent moment and Olive tail moment) when compared with the control groups (SC and RES) and with the varicocelized rats treated with resveratrol (V-RES group), showing that resveratrol reduced sperm DNA fragmentation produced by experimental varicocele (Table 7).

In a similar way, sperms collected from the ipsilateral and contralateral epididymides in varicocelized rats ( $V I$ and $V r$ respectively) had higher values of tail DNA percentage, comet tail length and comet tail extent moment when compared with those collected from the both sides (right and left) of the epididymis of the V-RES group ( $\mathrm{Vr}-\mathrm{RES}$ and $\mathrm{VI}-\mathrm{RES}$ ) and to the control groups (SC and RES) (Table 8).

\section{No significant reduction in testicular concentration of malondialdehyde was provided by resveratrol in varicocelized rats}

The malondialdehyde, a marker for lipid peroxidation, had increased levels in both of the varicocelized groups (V and V-RES) when compared with SC and RES groups (Fig. 3A). Data analyzed in each testis individually had a similar relationship among the varicocelized and control groups, as described above (Fig. 3B).

\section{Resveratrol reduced germ cell apoptosis in rats with varicocele}

TUNEL-positive cells were found in all control and experimental groups. The brown labeling and distribution of these TUNEL-positive cells in the testis of the rats can be observed in Figs 4 and 5 respectively.

As demonstrated in these figures, the varicocelized ( $V$ group - Figs 4C, D and 5) and varicocelized treated with resveratrol (V-RES group - Figs 4E, F and 5) groups had a significantly higher number of TUNEL-positive cells than the SC (Figs 4A and 5) and RES (Figs 4B and 5) groups. The ipsilateral testis of rats from the varicocele

Table 6 Data on sperm motility (CASA HTM-IVOS) of animals in the control and experimental groups, also considering the laterality in varicocelized groups ( $\mathrm{Vr}, \mathrm{VI}, \mathrm{Vr}$-RES, and $\mathrm{VI-RES)}$. Data are presented as mean \pm s.D. or as median (IQR: Q1-Q3).

\begin{tabular}{|c|c|c|c|c|c|c|}
\hline \multirow[b]{2}{*}{ Parameters } & \multicolumn{6}{|c|}{ Groups $(n=7)$} \\
\hline & SC & RES & $\mathrm{Vr}$ & VI & Vr-RES & VI-RES \\
\hline Motility $(\%)^{\mathrm{a}}$ & $97(94-97)$ & $98(94-98)$ & $88(82-96)^{\mathrm{c}}$ & $86(61-89)^{c, d}$ & $97(94-99)$ & $97(97-97.75)^{d}$ \\
\hline $\operatorname{VAP}(\mu \mathrm{m} / \mathrm{s})^{\mathrm{b}}$ & $247.9(238.8-265.9)$ & $247.8(215.4-259.3)$ & $236.3(223.6-243.5)$ & $234.1(211.6-265.8)$ & $245.9(225.8-261.3)$ & $273(253.9-278.1)$ \\
\hline $\operatorname{VSL}(\mu \mathrm{m} / \mathrm{s})^{\mathrm{b}}$ & $198.5(180.1-203.7)$ & $186.6(167.3-193.9)$ & $182.8(170.5-186.2)$ & 173.7 (160.5-184.1) & $193.4(168.9-196.8)$ & 205 (192.4-207.3) \\
\hline $\operatorname{VCL}(\mu \mathrm{m} / \mathrm{s})^{\mathrm{a}}$ & $377.3 \pm 40.4$ & $368.3 \pm 35.74$ & $344.8 \pm 28.35$ & $335.3 \pm 38.10$ & $367.5 \pm 26.91$ & $400.10 \pm 44.01$ \\
\hline $\mathrm{ALH}(\mu \mathrm{m})^{\mathrm{b}}$ & $13.09 \pm 2.80$ & $13.67 \pm 1.73$ & $11.72 \pm 1.05$ & $11.40 \pm 1.05$ & $13.42 \pm 1.40$ & $14.37 \pm 1.40$ \\
\hline $\mathrm{BCF}(\mathrm{Hz})^{\mathrm{a}}$ & $13.33 \pm 2.2$ & $13.9 \pm 2.52$ & $13.19 \pm 3.52$ & $14.13 \pm 2.7$ & $13.43 \pm 1.67$ & $13.21 \pm 1.77$ \\
\hline $\operatorname{STR}(\%)^{\mathrm{a}}$ & $73(72-74)$ & $72(72-73)$ & $74(74-77)$ & $75(72-79)$ & $73(71-75)$ & $72(70-73)$ \\
\hline LIN $(\%)^{\mathrm{a}}$ & $51.29 \pm 2.14$ & $50.12 \pm 2.64$ & $53.28 \pm 1.98$ & $54.0 \pm 3.83$ & $51.0 \pm 2.28$ & $50.33 \pm 2.5$ \\
\hline
\end{tabular}

${ }^{a} A N O V A$ and SNK. bAnalysis of Kruskal-Wallis and Dunn's test. ' $\mathrm{SC}, \mathrm{RES}$ and $\mathrm{Vr}-\mathrm{RES}>\mathrm{Vr}$ and $\mathrm{VI}$; ${ }^{\mathrm{d}} \mathrm{VI}<\mathrm{VI}-\mathrm{RES}(P<0.05)$. VAP, average path velocity; VSL, straight-line velocity; VCL, curvilinear velocity; ALH, amplitude of lateral head displacement; BCF, beat cross frequency; STR, straightness; LIN, linearity. 

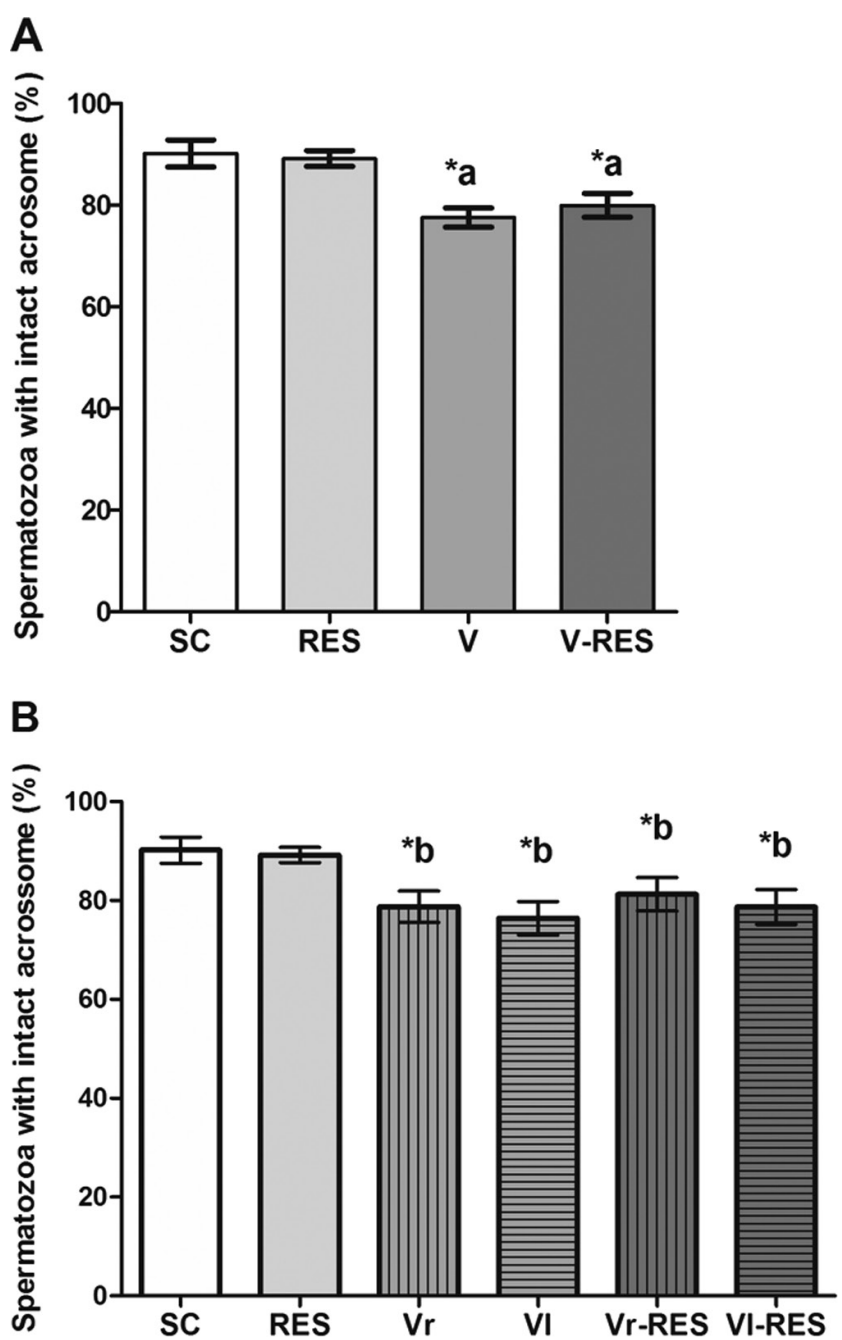

Figure 2 Percentage of spermatozoa with acrosome integrity from animals of the SC, RES, V and V-RES groups (A) and in SC, RES, Vr, VI (sides in $\mathrm{V}$ group), $\mathrm{Vr}$-RES and VI-RES (sides in V-RES group) (B) $(n=7)$. Values are expressed as mean and standard deviation. ANOVA and SNK. *a SC and RES $>$ V-RES $>$ V; *b SC and RES $>$ Vr, VI, Vr-RES and VI-RES;. $(P<0.05)$

group (VI - Figs 4C and 5) showed a higher number of TUNEL-positive cells when compared with the contralateral testis within the same group ( $\mathrm{Vr}$ - Figs 4D and 5), as well to both testes of the $\mathrm{V}$-RES group ( $\mathrm{Vr}$-RES and VI-RES - Figs 4E, F and 5) and also to the SC (Figs 4A and 5) and RES (Figs 4B and 5) groups. Data obtained from each testis individually had a similar relationship among the groups varicocelized and controls as described above (Fig. 5).

\section{Discussion}

The physiopathological mechanisms of varicocele that cause infertility are still not clear (Aitken et al. 2014). However, oxidative stress is widely believed to be the principal underlying pathology linking varicocele with male infertility (Tremellen et al. 2008, Aitken et al. 2014).

Alterations regarding the numerical density of germ cell apoptosis and various sperm quality parameters such as mitochondrial activity, acrosome integrity, motility, frequency of morphologically normal sperms, sperm DNA integrity, as well as testicular lipid peroxidation level were noted in the varicocelized group ( $\mathrm{V}$ group) used in this study. In addition, such alterations occurred in both ipsilateral and contralateral sides to the varicocele surgery. No disparity was observed between the results from the ipsilateral and contralateral sides of a same varicocelized group regarding almost all parameters studied, evidencing that the left-sided experimental varicocele had a comparable bilateral reproductive damage, except for the number of apoptotic germ cells, which was higher in the left testis. Thus, our data corroborate previous studies regarding
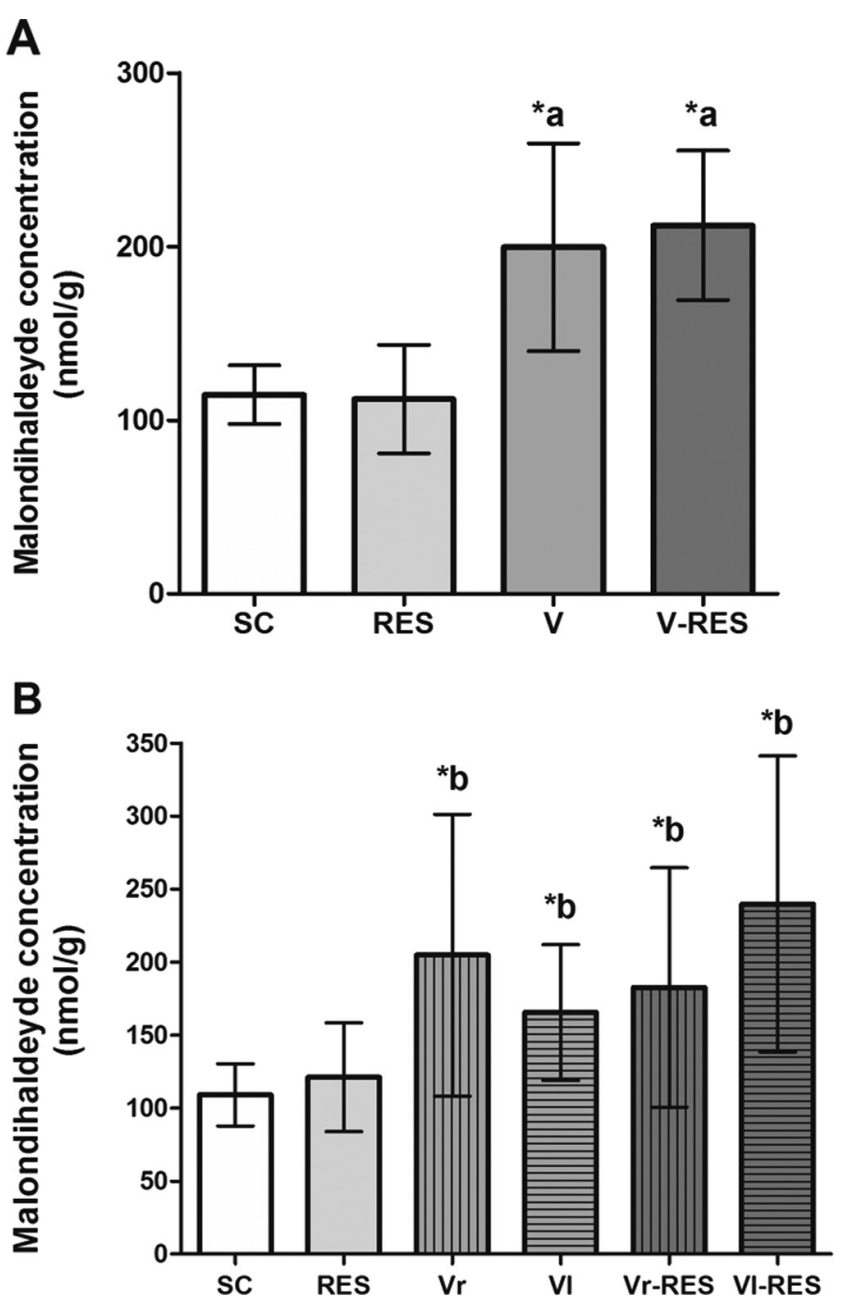

Figure 3 Testicular malondialdehyde concentration in animals of the $\mathrm{SC}, \mathrm{RES}, \mathrm{V}$ and $\mathrm{V}$-RES groups (A) and in the same groups but considering the laterality in the varicocelized rats $(\mathrm{Vr}, \mathrm{VI}, \mathrm{Vr}-\mathrm{RES}$ and VI-RES groups) (B) ( $n=7)$. Values are expressed as mean and standard deviation. ANOVA and SNK tests. *a $V$ and V-RES $>$ SC and RES; ${ }^{* b}$ $\mathrm{SC}$ and $\mathrm{RES}<\mathrm{Vr}, \mathrm{VI}, \mathrm{Vr}$-RES and $\mathrm{VI}-\mathrm{RES}(P<0.05)$. 
Table 7 Sperm DNA fragmentation (Comet assay) of animals in the control and experimental groups. Data are presented as mean \pm S.D. or as median (IQR: Q1-Q3).

\begin{tabular}{|c|c|c|c|c|}
\hline \multirow[b]{2}{*}{ Parameters } & \multicolumn{4}{|c|}{ Groups $(n=7)$} \\
\hline & SC & RES & $\mathrm{V}$ & V-RES \\
\hline$\%$ Tail DNA & $1.84 \pm 0.76$ & $1.67 \pm 0.65$ & $3.88 \pm 1,06^{c}$ & $2.33 \pm 0.34$ \\
\hline Tail length $(\mu \mathrm{m})^{b}$ & $8.03(6.63-15.35)$ & $11.66(6.09-14.89)$ & $22.06(18.44-40.92)^{\mathrm{c}}$ & $14.65(12.58-15.47)$ \\
\hline Tail moment ${ }^{b}$ & $0.20(0.12-0.56)$ & $0.22(0.12-0.51)$ & $1.03(0.84-2.51)^{\mathrm{c}}$ & $0.49(0.39-0.53)$ \\
\hline Olive moment ${ }^{b}$ & $0.25(0.15-0.58)$ & $0.20(0.15-0.48)$ & $0.66(0.62-1.47)^{c}$ & $0.40(0.29-0.47)$ \\
\hline
\end{tabular}

${ }^{\mathrm{a} A N O V A}$ and SNK. ${ }^{\mathrm{b}}$ Analysis of Kruskal-Wallis and SNK. ${ }^{\mathrm{C}} \mathrm{V}>\mathrm{SC}$, RES and V-RES $(P<0.05)$.

the testicular contralateral injury in rats submitted to left-sided experimental varicocele (Wang et al. 2010, Liu \& Ding 2014).

Although oxidative stress (OS) is an important factor in the sperm lesion caused by varicocele (Aitken et al. 2014) and in spite of the known efficacy of resveratrol as an antioxidant (Pinto et al. 1999, Saiko et al. 2008), its capability to decrease lipid peroxidation caused by varicocele in the testicular environment and in the epididymal level were not yet investigated. In the present research, we observed a favorable action of resveratrol on reproduction of rats submitted to a left-sided surgical varicocele. Indeed, in the results presented here, resveratrol significantly improved sperm qualitative parameters in these rats. However, the present data indicated that the relatively high dose of resveratrol used here did not relieve the lipid peroxidation caused by varicocele at the testicular level. To the best of our knowledge, other biomarkers of OS should also be investigated to better clarify its antioxidant potential in this circumstance. We cannot exclude the possibility that different mechanisms of antioxidant activity may have occurred. Besides, both levels of ROS and antioxidant mechanisms vary between testicular and epididymal environments. In fact, a reduction in glutathione peroxidase activity and an elevation in the malondialdehyde levels in theepididymis of varicocelized rats was already reported (QU et al. 2011). However, in the study presented here, we did not assess the OS in the epididymis.

Regarding the OS imbalance and its consequences to male fertility, some remarks have been mentioned in the literature: (i) plasma membrane lipid peroxidation, which damages fluidity and permeability of the membrane and inactivates membrane-bound receptors (Tremellen 2008); (ii) reduction in hyperactivation, motility and acrosome reaction through the change in the cyclic

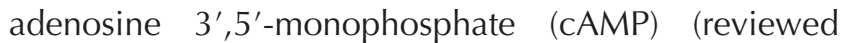
by Agarwal et al. 2014); (iii) direct damage on sperm DNA such as strand breaks, crosslinks, chromosomal deletions, rearrangements and polymorphism (Hosen et al. 2015, reviewed by Tremellen 2008, Makker et al. 2009).

Lipid peroxidation of the sperm cellular membrane may also affect sperm structure in many different ways - by disrupting the acrosome, the intermediate piece and the axoneme - which will interfere with the capacitation process, the acrosome reaction and sperm viability. Besides, sperms have little cytoplasm and low antioxidant status, what makes them more susceptible to the effects of direct oxidative stress (Shefi \& Turek 2006). The abundant concentration of PUFA and cholesterol present in the cellular membrane of mature sperms (Ko et al. 2014, Mendeluk et al. 2015) provides the necessary fluidity for the occurrence of the fusogenic events associated with the fertilization process (Nordberg \& Arnér 2001); however, it also makes them more vulnerable to oxidative stress (Lenzi et al. 2000). A high ROS production along with a reduction in the total antioxidant capacity (Tramer et al. 1998) can impair the fluidity of the plasma membrane of the sperm and raise sperm DNA damage (Miyaoka \& Esteves 2012).

In varicocelized rats, all of the aforementioned membrane structures are vulnerable to the process of lipid peroxidation occurred from the reaction between ROS and PUFA, or even to autocatalytic processes that produce toxic substances such as malondialdehyde (Slater 1984, Sharma \& Agarwal 1996, Benedetti et al. 2012). Also, an imbalance between the production of ROS and the antioxidant capacity can result in the acidification of the seminal plasma in men with varicocele, which impairs sperm motility and inhibits the activity of antioxidant enzymes (Ghabili et al. 2009).

Table 8 Sperm DNA fragmentation (Comet assay) of animals in the control and experimental groups. Values are expressed as median (IQR: Q1-Q3)

\begin{tabular}{|c|c|c|c|c|c|c|}
\hline \multirow[b]{2}{*}{ Parameters } & \multicolumn{6}{|c|}{ Groups $(n=7)$} \\
\hline & SC & RES & $\mathrm{Vr}$ & $\mathrm{Vl}$ & Vr-RES & VI-RES \\
\hline \% Tail DNA & $1.62(1.15-2.63)$ & $1.5(1.17-2.24)$ & $3.74(2.57-3.95)$ & $4.08(3.15-5.81)$ & $2.08(2.04-2.60)$ & $2.32(2.13-2.75)$ \\
\hline Tail length $(\mu \mathrm{m})$ & $8.03(6.63-5.35)$ & $11.66(6.09-4.89)$ & $18.79(16.58-41.82)$ & $20.33(18.67-44.16)$ & $15.89(12.59-16.84)$ & $12.88(12.57-13.87)$ \\
\hline Tail moment & $0.20(0.12-0.56)$ & $0.22(0.12-0.51)$ & $0.93(0.65-1.87)$ & $1.15(0.74-3.43)^{\mathrm{a}}$ & $0.47(0.35-0.50)$ & $0.51(0.36-0.52)$ \\
\hline Olive moment & $0.25(0.15-0.48)$ & $0.20(0.15-0.48)$ & $0.87(0.51-0.91)$ & $0.82(0.52-2.06)$ & $0.43(0.36-0.49)$ & $0.42(0.31-0.46)$ \\
\hline
\end{tabular}

Analysis of Kruskal-Wallis and SNK. Values are expressed as median and interquartile range (Q1-Q3); ${ }^{\mathrm{Vr}}$ and $\mathrm{VI}>\mathrm{SC}, \mathrm{RES}, \mathrm{Vr}-\mathrm{RES}$ and $\mathrm{VI}-\mathrm{RES}$ $(P<0.05)$ 


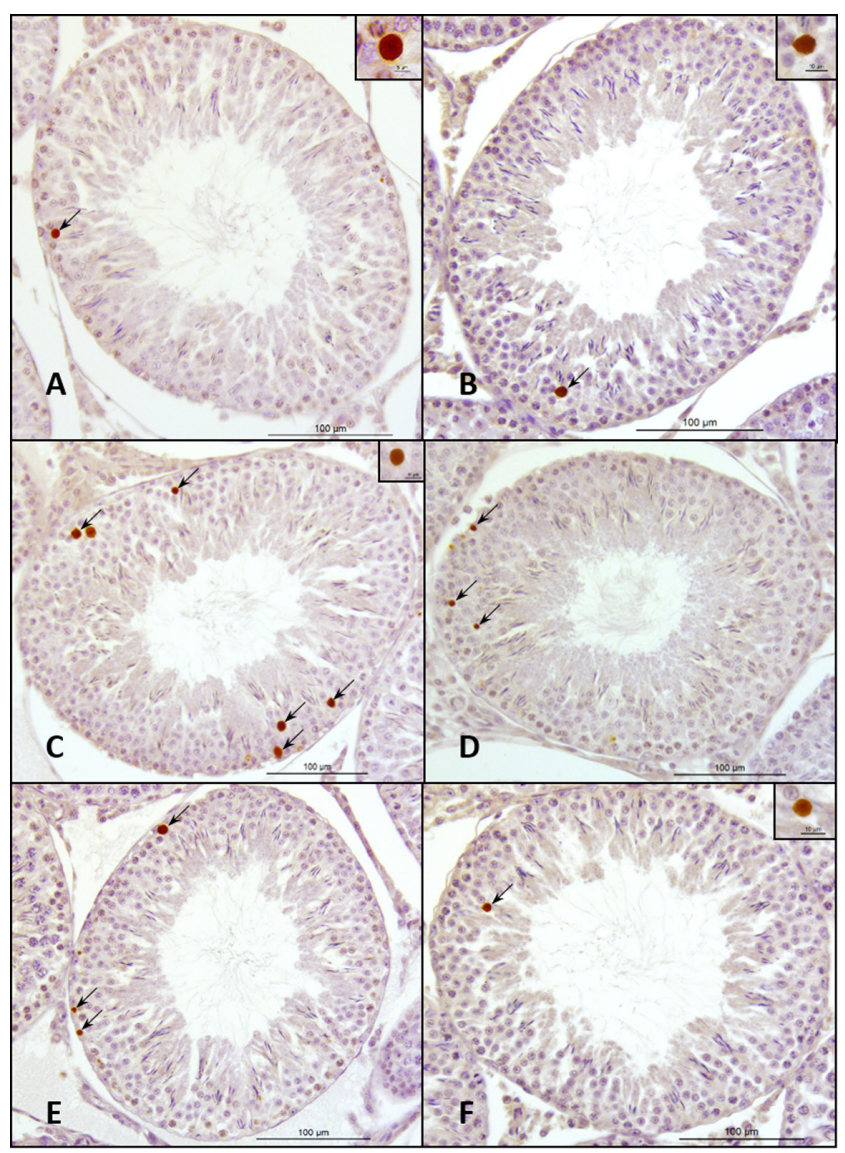

Figure 4 Photomicrographs of testicular cross sections of rats submitted to the TUNEL method, evidencing apoptotic germ cells (long arrows). Observe the seminiferous tubule sections of 100-day-old rats from the $\mathrm{SC}(\mathrm{A}), \mathrm{RES}(\mathrm{B}), \mathrm{VI}(\mathrm{C}), \mathrm{Vr}(\mathrm{D}), \mathrm{VI}-\mathrm{RES}(\mathrm{E})$ and $\mathrm{Vr}$-RES (F) groups, showing the TUNEL-positive cells brown-labeling; see the details. In the figures referring to the varicocele group $(C$ and $D)$ and varicocele treated with resveratrol $(E$ and $F)$, there was a greater number of labeled cells compared with sham-control group (A) and resveratrol (B). Bar $100 \mu \mathrm{m}$ on photomicrographs and $10 \mu \mathrm{m}$ on details.

Therefore, as a consequence of excess of ROS, reduction of sperm viability, capacitation and acrosome reaction can occur and lead to infertility.

An increase in DNA oxidative damage within spermatogonia and spermatocytes was also noted in testicular biopsies from men with varicoceleassociated oxidative stress (Tremellen 2008). We believe that the general low sperm quality observed in our ELV study could be a consequence of the damage caused by varicocele-induced ROS on not only the germ cells, during spermatogenesis in the testis, but also during the maturation process, in the epididymis (Tramer et al. 1998).

Along with the increase in ROS level, there is an augmented rate of apoptosis both in testis and in semen of men presenting varicocele (Simşek et al. 1998, Hendin et al. 1999). Indeed, the elevation of scrotal temperature produced in this condition produces heat stress within the testicular tissue, elevates oxidative stress, impairs spermatogenesis progression, and increases germ cell apoptosis (Shiraishi et al. 2010). The disruption of mitochondrial membranes and the release of cytochrome $c$ can also take place as a response to the increase in the oxidative stress, then activating caspases, which are effector proteases engaged in the apoptotic process (Agarwal \& Saleh 2002, Saleh \& Agarwal 2002, Makker et al. 2009). Despite the different hypotheses proposed to explain the reproductive damage caused by varicocele on male reproduction and the physiopathological mechanisms involved, they all seem to culminate in a common point: apoptosis (Wang et al. 2010).

In this study, an increase in the number of TUNELpositive cells occurred in both testes, but it was higher in the ipsilateral testis. Concerning the rate of germ cell apoptosis, our data are in accordance with those of Benoff et al. (2004), gathered from varicocele patients,
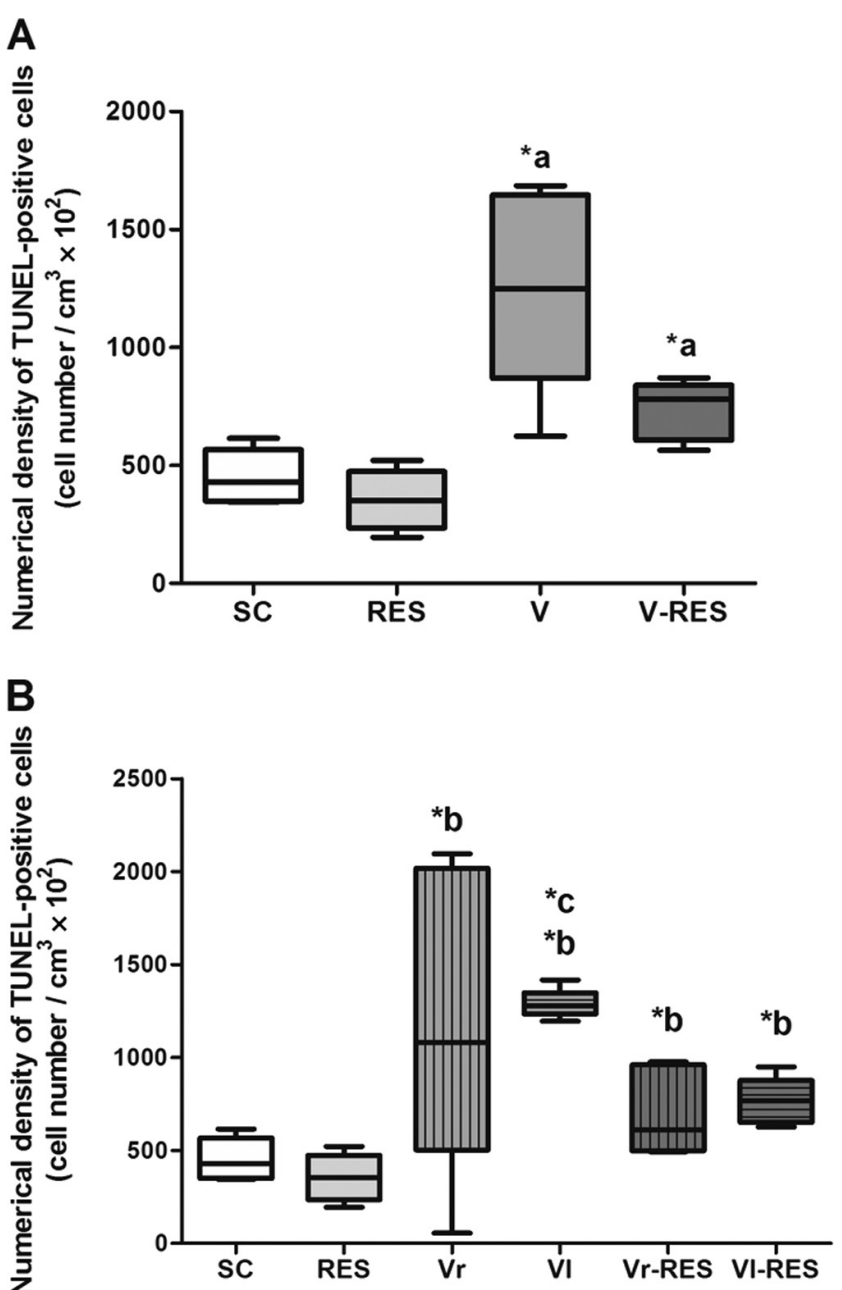

Figure 5 Box plot illustrating the distribution of data on the numerical density of TUNEL-positive cells of SC, RES, V and V-RES groups (A) and SC, RES, Vr, VI, Vr-RES and Vl-RES groups (B) $(n=5)$. Values are expressed as median and interquartile ranges (Q1-Q3), KruskalWallis analysis and SNK. *a V and V-RES > SC and RES; *b Vr, Vl, $\mathrm{Vr}$-RES and $\mathrm{VI}-\mathrm{RES}>\mathrm{SC}$ and RES; ${ }^{*} \mathrm{C} \mathrm{VI}>\mathrm{Vr}, \mathrm{Vr}$-RES and $\mathrm{VI}$-RES. 
and of Wang et al. (2010), who used adult varicocelized rats. However, Barqawi et al. (2004) observed an important increase in germ cell apoptosis only in the ipsilateral testis of varicocelized rats, in comparison to the control rats. Conversely, Lee et al. (2009), after examining the testes of adult varicocelized rats, found a higher frequency of apoptotic germ cells in both sides, although in the contralateral testis it happened later. Either the intervals of killing used to assess the effects of varicocele or the age when the ELV was induced could explain some divergences among the results reported by different authors, using the rat model.

In the results presented here, resveratrol reduced apoptosis rate in ipsilateral testis of varicocelized rats. Abdel-Dayem (2009) also described benefits of resveratrol to the spermatogenesis, in a histological analysis, in both testes of ELV in rats, although the extension of the effects to the germ cell death was not addressed in this study.

As germinal lineage is the major testicular component that implies in normal testicular volume, increased germ cell loss due to apoptosis leads to hypotrophy of the seminiferous epithelium, which may reflect in changes in the testicular morphometric parameters. Thus, the other important and indirect evidence linked to male infertility in varicocele patients is the reduction of the testicular volume. Indeed, testicular asymmetry is the first evidence of the presence of varicocele, especially in adolescents (Paduch \& Skoog 2001). In addition, reduction of testicular size is generally an indicative of reduced spermatogenesis (Jarow 2001). AbdelDayem (2009) also showed that germ cell proliferation is protected by resveratrol under ELV in adult rats. Therefore, the current research corroborates the previous data, showing bilateral alterations of the testicular size in varicocelized rats and suggesting that resveratrol has potential to prevent the damage associated with the condition.

In our research, RES partially reduced testicular apoptosis and reverted alterations in sperm motility, acrosome integrity, mitochondrial activity and DNA fragmentation in the ipsilateral side to the varicocele surgery. In the contralateral side, there was also improvement of some parameters such as sperm motility, mitochondrial activity and DNA integrity. Regarding the motility and the DNA fragmentation, the sham-control, resveratrol and resveratrol/varicocelized results were close. In summary, we consider that the present results support the observations made by other authors concerning some of the most common reproductive changes in varicocele reported so far, regarding the following parameters: (i) sperm DNA integrity (Blumer et al. 2012, La Vignera et al. 2012, Tavalaee et al. 2014), (ii) mitochondrial function (Blumer et al. 2012, La Vignera et al. 2012), (iii) sperm chromatin condensation (La Vignera et al. 2012, Tavalaee et al. 2014), (iv) sperm normal morphology
(Blumer et al. 2012, Tavalaee et al. 2014), (v) acrosome integrity (Blumer et al. 2012, Tavalaee et al. 2014) and (vi) DNA protamination and apoptosis index (La Vignera et al. 2012, Wang et al. 2010).

As mentioned previously, resveratrol improved most of the sperm quality parameters studied and acted reducing the apoptosis rate in the ipsilateral testis. Ultimately, treatment with antioxidants has been studied as an alternative or adjunctive therapy to avoid male infertility, even when related to varicocele (Hamada et al. 2013). Based on the present results and respecting the interspecies differences, we believe that resveratrol may represent, in the future, a valuable adjunctive compound in the treatment of patients with varicocele, which reinforces previous observations (Abdel-Dayem 2009). The reproductive performance and capacity of the animals, the epididymal oxidative stress, the DNA protamination and the PUFA level as a marker of sperm pathology are current objects of study of our group, aiming to better understand the protective role of the resveratrol and its mechanisms to prevent varicocelerelated infertility.

\section{Declaration of interest}

The authors declare that there is no conflict of interests regarding the publication of this article.

\section{Funding}

This work was financially supported by The National Council for the Improvement of Higher Education (CAPES/Brazil) and the Laboratory of Human Reproduction - Unifesp for providing the equipment used in the sperm motility analyzes.

\section{Acknowledgements}

The authors thank CAPES/Brazil for the financial support.

\section{References}

Abd-Allah AR, Helal GK, Al-Yahya AA, Aleisa AM, Al-Rejaie SS \& Al-Bakheet SA 2009 Pro-inflammatory and oxidative stress pathways which compromise sperm motility and survival may be altered by L-carnitine. Oxidative Medicine and Cellular Longevity 2 73-81. (doi:10.4161/oxim.2.2.8177)

Abdel-Dayem MM 2009 Histological and Immunohistochemical changes in the adult rat testes after left experimental varicocele and possible protective effects of resveratrol. Egyptian Journal of Histology 32 81-90.

Agarwal A \& Saleh RA 2002 Role of oxidants in male infertility: rationale, significance, and treatment. Urologic Clinics of North America 29 817-827. (doi:10.1016/S0094-0143(02)00081-2)

Agarwal A, Hamada A \& Esteves SC 2012 Insight into oxidative stress in varicocele-associated male infertility: part 1. Nature Reviews Urology 9 678-690. (doi:10.1038/nrurol.2012.197)

Agarwal A, Virk G, Ong C \& du Plessis SS 2014 Effect of oxidative stress on male reproduction. World Journal of Men's Health 32 1-17. (doi:10.5534/wjmh.2014.32.1.1) 
Aitken RJ \& Roman SD 2008 Antioxidant systems and oxidative stress in the testes. Oxidative Medicine and Cellular Longevity 1 15-24. (doi:10.4161/oxim.1.1.6843)

Aitken RJ, Smith TB, Jobling MS, Baker MA \& De Iuliis GN 2014 Oxidative stress and male reproductive health. Asian Journal of Andrology $\mathbf{1 6}$ 31-38. (doi:10.4103/1008-682X.122203)

Aprioku JS 2013 Pharmacology of free radicals and the impact of reactive oxygen species on the testis. Journal of Reproduction \& Infertility 14 158-172.

Barqawi A, Caruso A \& Meacham RB 2004 Experimental varicocele induces testicular germ cell apoptosis in the rat. Journal of Urology 171 501-503. (doi:10.1097/01.ju.0000088775.69010.61)

Benedetti S, Tagliamonte MC, Catalani S, Primiterra M, Canestrari F, De Stefani S, Palini S \& Bulletti C 2012 Differences in blood and semen oxidative status in fertile and infertile men, and their relationship with sperm quality. Reproductive Biomedicine Online 25 300-306. (doi:10.1016/j.rbmo.2012.05.011)

Benoff SH, Millan C, Hurley IR, Napolitano B \& Marmar JL 2004 Bilateral increased apoptosis and bilateral accumulation of cadmium in infertile men with left varicocele. Human Reproduction 19 616-627. (doi:10.1093/humrep/deh139)

Bhat KPL, Kosmeder JW \& Pezzuto JM 2001 Biological effects of resveratrol. Antioxidiant \& Redox Signaling 3 1041-1064. (doi:10.1089/ 152308601317203567)

Blumer CG, Restelli AE, Giudice PT, Soler TB, Fraietta R, Nichi M, Bertolla RP \& Cedenho AP 2012 Effect of varicocele on sperm function and semen oxidative stress. BJU International 109 259-265. (doi:10.1111/j.1464-410X.2011.10240.x)

Bong GW \& Koo HP 2004 The adolescent varicocele: to treat or not to treat. Urologic Clinics of North America 31 509-515. (doi:10.1016/j. ucl.2004.04.012)

Casey JT \& Misseri R 2015 Adolescent varicoceles and infertility. Endocrinology and Metabolism Clinics of North America 44 835-842. (doi:10.1016/j.ecl.2015.07.007)

Chen X, He H, Wang G, Yang B, Ren W, Ma L \& Yu Q 2007 Stereospecific determination of cis- and trans-resveratrol in rat plasma by HPLC: application to pharmacokinetic studies. Biomededical Chromatography 21 257-265. (doi:10.1002/(ISSN)1099-0801)

Codrington AM, Hales BF \& Robaire B 2004 Spermiogenic germ cell phasespecific DNA damage following cyclophosphamide exposure. Journal of Andrology 25 354-362. (doi:10.1002/j.1939-4640.2004.tb02800.x)

Das S, Lin HS, Ho PC \& Ng KY 2008 The impact of aqueous solubility and dose on the pharmacokinetic profiles of resveratrol. Pharmaceutical Research 25 2593-2600. (doi:10.1007/s11095-008-9677-1)

de la Lastra CA \& Villegas I 2005 Resveratrol as an anti-inflammatory and anti-aging agent: mechanisms and clinical implications. Molecular Nutrition \& Food Research 49 405-430. (doi:10.1002/mnfr.200500022)

Delaney DP, Carr MC, Kolon TF, Snyder HM \& Zderic SA 2004 The physical characteristics of young males with varicocele. BJU International 94 624-626. (doi:10.1111/bju.2004.94.issue-4)

delBarco-Trillo J, Mateo R \& Roldan ER 2015 Differences in the fatty-acid composition of rodent spermatozoa are associated to levels of sperm competition. Biology Open 4 466-473. (doi:10.1242/bio.201411288)

Dohle GR, Colpi GM, Hargreave TB, Papp GK, Jungwirth A, Weidner W \& EWGoM Infertility 2005 EAU guidelines on male infertility. European Urology 48 703-711. (doi:10.1016/j.eururo.2005.06.002)

Domínguez C, Guillén DA \& Barroso CG 2001 Automated solid-phase extraction for sample preparation followed by high-performance liquid chromatography with diode array and mass spectrometric detection for the analysis of resveratrol derivatives in wine. Journal of Chromatography A 918 303-310. (doi:10.1016/S0021-9673(01)00748-8)

Ferramosca A, Albani D, Coppola L \& Zara V 2015 Varicocele negatively affects sperm mitochondrial respiration. Urology 86 735-739. (doi:10.1016/j.urology.2015.07.011)

Filler R 1993 Methods for evaluation of rat epididymal sperm morphology. In Male Reproductive Toxicology, pp 334-343. Eds RE Chapin \& JJ Heindel. San Diego, CA, USA: Academic Press. (doi:10.1016/B978-012-461207-5.50025-0)

Frémont L 2000 Biological effects of resveratrol. Life Science 66 663-673. (doi:10.1016/S0024-3205(99)00410-5)

Gambini J, Inglés M, Olaso G, Lopez-Grueso R, Bonet-Costa V, GimenoMallench L, Mas-Bargues C, Abdelaziz KM, Gomez-Cabrera MC,
Vina J et al. 2015 Properties of resveratrol: in vitro and in vivo studies about metabolism, bioavailability, and biological effects in animal models and humans. Oxidative Medicine and Cellular Longevity 2015 837042. (doi:10.1155/2015/837042)

Ghabili K, Shoja MM, Agutter PS \& Agarwal A 2009 Hypothesis: intracellular acidification contributes to infertility in varicocele. Fertility and Sterility 92 399-401. (doi:10.1016/j.fertnstert.2008.05.070)

Gil-Villa AM, Cardona-Maya W, Agarwal A, Sharma R \& Cadavid A 2009 Role of male factor in early recurrent embryo loss: do antioxidants have any effect? Fertility and Sterility 92 565-571. (doi:10.1016/j. fertnstert.2008.07.1715)

Gulcin I 2010 Antioxidant properties of resveratrol: A structure-activity insight. Innovative Food Science \& Emerging Technologies 11 210-218. (doi:10.1016/j.ifset.2009.07.002)

Haines GA, Hendry JH, Daniel CP \& Morris ID 2002 Germ cell and dose-dependent DNA damage measured by the comet assay in murine spermatozoaa after testicular X-irradiation. Biology of Reproduction 67 854-861. (doi:10.1095/biolreprod.102.004382)

Hall JC, Hadley J \& Doman T 1991 Correlation between changes in rat sperm membrane lipids, protein, and the membrane physical state during epididymal maturation. Journal of Andrology 12 76-87. (doi:10.1002/j.1939-4640.1991.tb00220.x)

Hamada A, Esteves SC \& Agarwal A 2013 Insight into oxidative stress in varicocele-associated male infertility: part 2. Nature Reviews Urology 10 26-37. (doi:10.1038/nrurol.2012.198)

Harikumar KB \& Aggarwal BB 2008 Resveratrol - a multitargeted agent for age-associated chronic diseases. Cell Cycle 7 1020-1035. (doi:10.4161/ cC.7.8.5740)

Hawk CT, Leary S \& Morris T 2005 Formulary for Laboratory Animals. Ames, IA, USA: Wiley.

Hendin BN, Kolettis PN, Sharma RK, Thomas AJ \& Agarwal A 1999 Varicocele is associated with elevated spermatozoal reactive oxygen species production and diminished seminal plasma antioxidant capacity. Journal of Urology 161 1831-1834. (doi:10.1016/S00225347(05)68818-0)

Hosen MB, Islam MR, Begum F, Kabir Y \& Howlader MZ 2015 Oxidative stress induced sperm DNA damage, a possible reason for male infertility. Iranian Journal of Reproductive Medicine 13 525-532.

Hrudka F 1987 Cytochemical and ultracytochemical demonstration of cytochrome c oxidase in spermatozoa and dynamics of its changes accompanying ageing or induced by stress. International Journal of Andrology 10 809-828. (doi:10.1111/j.1365-2605.1987.tb00385.x)

Jang JH \& Surh YJ 2001 Protective effects of resveratrol on hydrogen peroxide-induced apoptosis in rat pheochromocytoma (PC12) cells. Mutation Research 496 181-190. (doi:10.1016/S13835718(01)00233-9)

Jang M, Cai L, Udeani GO, Slowing KV, Thomas CF, Beecher CW, Fong HH, Farnsworth NR, Kinghorn AD, Mehta RG et al. 1997 Cancer chemopreventive activity of resveratrol, a natural product derived from grapes. Science 275 218-220. (doi:10.1126/ science.275.5297.218)

Jarow JP 2001 Effects of varicocele on male fertility. Human Reproduction Update 7 59-64. (doi:10.1093/humupd/7.1.59)

Jarow JP, Coburn M \& Sigman M 1996 Incidence of varicoceles in men with primary and secondary infertility. Urology 47 73-76. (doi:10.1016/ S0090-4295(99)80385-9)

Juan ME, González-Pons E, Munuera T, Ballester J, Rodríguez-Gil JE \& Planas JM 2005 trans-Resveratrol, a natural antioxidant from grapes, increases sperm output in healthy rats. Journal of Nutrition 135 757-760.

Kefer JC, Agarwal A \& Sabanegh E 2009 Role of antioxidants in the treatment of male infertility. International Journal of Urology $\mathbf{1 6}$ 449-457. (doi:10.1111/j.1442-2042.2009.02280.x)

Klinefelter GR, Gray LE \& Suarez JD 1991 The method of sperm collection significantly influences sperm motion parameters following ethane dimethanesulphonate administration in the rat. Reproductive Toxicology 5 39-44. (doi:10.1016/0890-6238(91)90108-R)

Ko EY, Sabanegh ES \& Agarwal A 2014 Male infertility testing: reactive oxygen species and antioxidant capacity. Fertility and Sterility 102 1518-1527. (doi:10.1016/j.fertnstert.2014.10.020)

La Vignera S, Condorelli R, Vicari E, D Agata R \& Calogero AE 2012 Effects of varicocelectomy on sperm DNA fragmentation, mitochondrial 
function, chromatin condensation, and apoptosis. Journal of Andrology 33 389-396. (doi:10.2164/jandrol.111.013433)

Lee JD, Lee TH, Cheng WH \& Jeng SY 2009 Involved intrinsic apoptotic pathway of testicular tissues in varicocele-induced rats. World Journal of Urology 27 527-532. (doi:10.1007/s00345-008-0367-8)

Lenzi A, Gandini L, Picardo M, Tramer F, Sandri G \& Panfili E 2000 Lipoperoxidation damage of spermatozoa polyunsaturated fatty acids (PUFA): scavenger mechanisms and possible scavenger therapies. Frontiers in Bioscience $\mathbf{5}$ E1-E15.

Liu J \& Ding D 2014 Varicocele-caused progressive damage in bilateral testis and sertoli cell-only syndrome in homolateral testis in rats. Medical Science Monitor 20 1931-1936. (doi:10.12659/MSM.891324)

Makker K, Agarwal A \& Sharma R 2009 Oxidative stress \& male infertility. Indian Journal of Medical Research 129 357-367.

Mendeluk GR, Cohen MI, Ferreri C \& Chatgilialoglu C 2015 Nutrition and reproductive health: sperm versus erythrocyte lipidomic profile and $\omega-3$ intake. Journal of Nutrition and Metabolism 2015670526. (doi:10.1155/2015/670526)

Miraglia SM \& Hayashi H 1993 Histomorphometry of immature rat testis after heating. Journal of Morphology 217 65-74. (doi:10.1002/ (ISSN)1097-4687)

Miranda-Spooner M, Paccola CC, Neves FM, de Oliva SU \& Miraglia SM 2016 Late reproductive analysis in rat male offspring exposed to nicotine during pregnancy and lactation. Andrology 4 218-231. (doi:10.1111/ andr.12100)

Miyaoka R \& Esteves SC 2012 A critical appraisal on the role of varicocele in male infertility. Advances in Urology 2012597495.

Nasr Esfahani MH \& Tavalaee M 2012 Origin and role of DNA damage in varicocele. International Journal of Fertility and Sterility $\mathbf{6} 141-146$.

Naughton CK, Nangia AK, \& Agarwal A 2001 Pathophysiology of varicoceles in male infertility. Human Reproduction Update 7 473-481. (doi:10.1093/humupd/7.5.473)

Nordberg J \& Arnér ES 2001 Reactive oxygen species, antioxidants, and the mammalian thioredoxin system. Free Radical Biology \& Medicine 31 1287-1312. (doi:10.1016/S0891-5849(01)00724-9)

Paduch DA \& Skoog SJ 2001 Current management of adolescent varicocele. Reviews in Urology 3 120-133.

Pinto MC, García-Barrado JA \& Macías P 1999 Resveratrol is a potent inhibitor of the dioxygenase activity of lipoxygenase. Journal of Agricultural and Food Chemistry 47 4842-4846. (doi:10.1021/ jf990448n)

Qu XW, Shan Z], Han QH, Hu JT, Zhang PH \& Zhang SW 2011 [Effects of Qiangjing Capsule on the oxidative and antioxidative system in the epididymis of varicocele rats]. Zhonghua Nan Ke Xue 17 1039-1042.

Razi M \& Malekinejad H 2015 Varicocele-induced infertility in animal models. International Journal of Fertility and Sterility 9 141-149.

Reyes JG, Farias JG, Henríquez-Olavarrieta S, Madrid E, Parraga M, Zepeda AB \& Moreno RD 2012 The hypoxic testicle: physiology and pathophysiology. Oxidative Medicine and Cellular Longevity 2012 929285. (doi:10.1155/2012/929285)

Saiko P, Szakmary A, Jaeger W \& Szekeres T 2008 Resveratrol and its analogs: defense against cancer, coronary disease and neurodegenerative maladies or just a fad? Mutation Research 658 68-94. (doi:10.1016/j. mrrev.2007.08.004)

Saleh RA \& Agarwal A 2002 Oxidative stress and male infertility: from research bench to clinical practice. Journal of Andrology 23 737-752. (doi:10.1002/j.1939-4640.2002.tb02324.x)

Saypol DC, Howards SS, Turner TT \& Miller ED 1981 Influence of surgically induced varicocele on testicular blood flow, temperature, and histology in adult rats and dogs. Journal of Clinical Investigation $\mathbf{6 8}$ 39-45. (doi:10.1172/JCI110252)

Scherle W 1970 A simple method for volumetry of organs in quantitative stereology. Mikroskopie 26 57-60.

Sharma RK \& Agarwal A 1996 Role of reactive oxygen species in male infertility. Urology 48 835-850. (doi:10.1016/S0090-4295(96)00313-5)

Shefi S \& Turek PJ 2006 Definition and current evaluation of subfertile men. International Brazilian Journal of Urology 32 385-397. (doi:10.1590/ S1677-55382006000400002)
Shiraishi K, Takihara H \& Matsuyama H 2010 Elevated scrotal temperature, but not varicocele grade, reflects testicular oxidative stress-mediated apoptosis. World Journal of Urology 28 359-364. (doi:10.1007/s00345-009-0462-5)

Shorr E 1941 A new technic for staining vaginal smears: III, a single differential stain. Science 94 545-546. (doi:10.1126/science.94.2449.545-a)

Simşek F, Türkeri L, Cevik I, Bircan K \& Akdaş A 1998 Role of apoptosis in testicular tissue damage caused by varicocele. Archivos Españoles de Urología 51 947-950.

Skoog SJ, Roberts KP, Goldstein M \& Pryor JL 1997 The adolescent varicocele: what s new with an old problem in young patients? Pediatrics 100 112-121. (doi:10.1542/peds.100.1.112)

Slater TF 1984 Overview of methods used for detecting lipid peroxidation. Methods in Enzymology 105 283-293. (doi:10.1016/S00766879(84)05036-9)

Stumpp T, Sasso-Cerri E, Freymüller E \& Miraglia SM 2004 Apoptosis and testicular alterations in albino rats treated with etoposide during the prepubertal phase. Anatomical Record Part A Discoveries in Molecular Cellular and Evolutionary Biology 279 611-622. (doi:10.1002/ ar.a.20045)

Tavalaee M, Bahreinian M, Barekat F, Abbasi H \& Nasr-Esfahani MH 2014 Effect of varicocelectomy on sperm functional characteristics and DNA methylation. Andrologia 47 904-909. (doi:10.1111/and.12345)

Tramer F, Rocco F, Micali F, Sandri G \& Panfili E 1998 Antioxidant systems in rat epididymal spermatozoa. Biology of Reproduction 59 753-758. (doi:10.1095/biolreprod59.4.753)

Trela BC \& Waterhouse AL 1996 Resveratrol: isomeric molar absorptivities and stability. Journal of Agricultural and Food Chemistry 445. (doi:10.1021/jf9504576)

Tremellen K 2008 Oxidative stress and male infertility - a clinical perspective. Hum Reproduction Update 14 243-258. (doi:10.1093/ humupd/dmn004)

Turner TT 2001 The study of varicocele through the use of animal models. Human Reproduction Update 7 78-84. (doi:10.1093/humupd/7.1.78)

Türedi S, Yulug `E, Alver A, Kutlu Ö \& Kahraman C 2015 Effects of resveratrol on doxorubicin induced testicular damage in rats. Experimental and Toxicologic Pathology 67 229-235. (doi:10.1016/j.etp.2014.12.002)

Varisli O, Uguz C, Agca C \& Agca Y 2009 Effect of chilling on the motility and acrosomal integrity of rat sperm in the presence of various extenders. Journal of the American Association for Laboratory Animal Science $\mathbf{4 8}$ 499-505.

Vendramini V, Robaire B \& Miraglia SM 2012 Amifostine-doxorubicin association causes long-term prepubertal spermatogonia DNA damage and early developmental arrest. Human Reproduction 27 2457-2466. (doi:10.1093/humrep/des159)

Vendramini V, Cedenho AP, Miraglia SM \& Spaine DM 2013 Reproductive function of the male obese Zucker rats: alteration in sperm production and sperm DNA damage. Reproductive Science 21 221-229. (doi:10.1177/1933719113493511)

Wang H, Sun Y, Wang L, Xu C, Yang Q, Liu B \& Liu Z 2010 Hypoxiainduced apoptosis in the bilateral testes of rats with left-sided varicocele: a new way to think about the varicocele. Journal of Andrology 31 299-305. (doi:10.2164/jandrol.108.007153)

Yulug E, Turedi S, Karaguzel E, Kutlu O, Mentese A \& Alver A 2014 The short term effects of resveratrol on ischemia-reperfusion injury in rat testis. Journal of Pediatric Surgery 49 484-489. (doi:10.1016/j. jpedsurg.2013.08.028)

Zhang Y, Gao X, Liu X, Wang K, Pang J \& Zhou J 2008 A new experimental inbred Wistar rat varicocele model: anatomy of the left spermatic vein and the effect on histology. Andrologia 40 13-17. (doi:10.1111/ (ISSN)1439-0272)

Received 14 January 2016

First decision 23 February 2016

Revised manuscript received 25 March 2016

Accepted 5 April 2016 